\title{
Contação de histórias em tempos de COVID- 19: estabelecendo vínculos afetivos entre professora, crianças e famílias
}

\author{
Storytelling in times of COVID-19: establishing affective \\ bond among teacher, children and families
}

\section{Contar histórias en tiempos de COVID-I9: estableciendo vínculos afectivos entre la maestra, los niños y las famílias}

\author{
Carolina Zasso Pigatto' \\ https://orcid.org/0000-000I-9096-1582 \\ Ivani Soares ${ }^{2}$ \\ https://orcid.org/0000-0002-1248-9689 \\ Celso llgo Henz ${ }^{3}$ \\ https://orcid.org/0000-0002-057I-5684
}

\begin{abstract}
Resumo: Este trabalho é o relato de experiência de uma professora de Educação Infantil, da Rede Municipal de Santa Maria, RS, a qual procura estabelecer e manter vínculos afetivos com crianças pequenas e suas famílias por meio de contato virtual com contações de histórias. Como aporte teórico, usa-se Wallon (2005), Vygotsky (1984), Pichon-Rivière (1998), Paulo Freire (1997, 20I I) e Marie-Christine Josso (2010). Durante essa vivência, em meio à pandemia de COVID-19, pelo contato através das redes sociais, principalmente via whatsapp, é possível perceber que esse tipo de proposta pedagógica proporciona a auto(trans)formação da professora e momentos lúdicos às crianças e aos seus familiares. As contações de histórias mantêm e estreitam vínculos afetivos estabelecidos, bem como possibilitam que relações de confiança e de ajuda mútua sejam consolidadas.

Palavras-chave: Vínculos afetivos. Contações de histórias. COVID-19.
\end{abstract}

Abstract: This study is the experience report of an early childhood education teacher from a municipal school in Santa Maria, R.S. The teacher tries to establish and keep affective bonds with the little children and their families through the virtual contact using the storytelling. As theorical contributions were used Wallon (2005), Vygotsky (1984), Pichon- Reviére (1998), Paulo Freire (1997-20II) and Marie- Christine Jasso (2010). During this

\footnotetext{
' Mestra em Educação da Universidade Federal de Santa Maria (UFSM). Professora de Educação Infantil da Rede Pública de Santa Maria, RS. E-mail: carolzpigatto@gmail.com

${ }^{2}$ Mestra em Educação pela Universidade Federal de Santa Maria (UFSM). Secretária Executiva na Fundação Universidade Federal do Pampa (Unipampa). E-mail: ivanirodhen@gmail.com

${ }^{3}$ Pós-Doutor pela Universidad de Sevilla, Sevilla/ Espanha. Professor titular da Universidade Federal de Santa Maria (UFMS). E-mail: celsoufsm@gmail.com
} 
experience, in the middle of COVID-19 pandemic, keeping in touch through social media, mainly by WhatsApp, it is possible to notice that this kind of pedagogical proposal provides the self -(trans) formation of the teacher and playful moments to children and their families. The storytelling keeps and narrows affective bonds established, as well as these stories enable to reliable relationships and mutual help be consolidated.

Keywords: Affective bonds. Telling stories. COVID - 19.

Resumen: Este trabajo es el relato de la experiencia de una Maestra de Educación Infantil de la Red Municipal de Santa Maria, RS, la cual busca establecer y mantener vínculos afectivos con los niños y sus famílias por intermédio del contacto virtual, contando histórias. Como aporte teórico fué utilizado Wallon (2005), Vygotsky (1984), Pichon-Rivière (1998), Paulo Freire (1997, 201 I) y Marie-Christine Josso (2010). Durante esa vivencia, en medio a la pandemia de COVID-19, por el contacto através de las redes sociales, principalmente via whatsapp, es posible percibir que ese tipo de propuesta pedagógica proporciona la auto(trans)formación de la maestra y momentos lúdicos a los niños y sus familiares. Contar histórias mantiene y estrecha los vínculos afectivos establecidos, como también posibilita que relaciones de confianza y de ajuda mútua sean consolidadas.

Palabras-clave: Vínculos afectivos. Contando histórias. COVID-I9.

\section{Introdução}

O tema deste trabalho é uma reflexão sobre os esforços de uma professora da primeira etapa da Educação Básica (Educação Infantil), para manter e estreitar os vínculos afetivos já estabelecidos com as crianças e suas famílias no curto espaço de tempo entre o início das aulas e a paralização delas em face da pandemia de COVID-19, por meio de contações de histórias.

Em tempos de pandemia e de distanciamento social, surge, para os docentes, 0 questionamento: como estabelecer e manter os vínculos afetivos com as crianças e suas famílias? Ressalta-se a auto(trans)formação da docente no fazer o que lhe é possível, no contexto em que atua, para manter o contato com os sujeitos envolvidos.

O ambiente de atuação é uma Escola Pública de Educação Infantil do município de Santa Maria/RS, com uma turma de Berçário II (B-II: crianças de I ano e meio a 2 anos) e Maternal II (M-II: crianças de 3 anos e meio a 4 anos). O esforço é para manter os vínculos afetivos já estabelecidos, ampliando-os, para que permaneçam e sejam consolidados, mesmo sem a presença física que possibilita o olhar, o toque e a comunicação verbal e não verbal, vitais para a convivência e o aprendizado mútuos.

A intenção desta escrita não é dialogar sobre "dimensões estéticas da leitura literária infantil” (CHAVES e KOEHLER, 202I, p. 42I) nem sobre as funções social e política da contação, mas relatar as vivências em disponibilizar um momento de leveza realizado com amorosidade, com a possibilidade de estabelecer vínculos afetivos entre os envolvidos, ou seja, os bebês e as crianças bem pequenas, com suas famílias, mediados pela professora no período pandêmico. Também, que esses momentos servissem para que cada um pudesse dizer a "sua palavra", demonstrar seus sentimentos.

Para ter um suporte teórico, usam-se conceitos de Wallon (1975, 197I), Vygotsky (1994), Pichon-Rivière (1998) e Paulo Freire (1997, 20I I).

Pondera-se a compreensão sobre a afetividade e os vínculos afetivos e aponta-se os meios usados para viabilizar a comunicação entre os sujeitos envolvidos, bem como ressaltar algumas 
vivências significativas.

É possível perceber que essa proposta pedagógica permite, pela ludicidade dos sentimentos vividos durante as contações de histórias, que as relações de confiança e a ajuda mútua sejam ampliadas e consolidadas.

\section{Importância dos vínculos afetivos estabelecidos}

\section{Estudos realizados}

Compreende-se que são estabelecidos vínculos afetivos através da convivência, da proximidade, da afetividade, dos sentimentos, das relações, das emoções e da comunicação, surgidos por meio da confiança mútua, das amizades, da afinidade e do coleguismo entre os sujeitos. A forma de se estabelecerem essas relações foi abruptamente modificada em face da pandemia. Sem aviso prévio, foi necessário reinventar-se, sempre considerando a faixa etária dos discentes envolvidos.

Assim, busca-se suporte teórico nas concepções de Wallon (2005) a respeito da afetividade que, tanto quanto a inteligência, tem papel imprescindível nos processos de desenvolvimento da personalidade das crianças. Os professores percebem o estado emotivo das crianças e desafiam-se a abordá-lo para ampliar o desenvolvimento dos sujeitos.

As atitudes mostram traços da personalidade e do caráter e demonstram o quanto a raiva, a alegria, a tristeza, o medo e os sentimentos mais íntimos adquirem funções importantes nas relações das crianças com o meio. A afetividade é o elemento mediador das relações sociais, uma vez que

[...] os gestos, a sua atitude, a sua fisionomia e a sua voz entram também no domínio da expressão, que deste modo tem uma acção dupla, eferente quando traduz os desejos da criança, aferente quanto à disposição que estes desejos encontram ou provocam nos outros. Esta reciprocidade estabelece-se tanto mais facilmente quanto ela parece estar dentro da natureza e do papel funcional das emoções. (WALLON, 2005, p. 154).

De acordo com o autor abordado, afetividade é o termo utilizado para identificar um domínio funcional abrangente, no qual aparecem variadas manifestações, que vão desde as primeiras, basicamente orgânicas, até as diferenciadas, como as emoções, os sentimentos e as paixões. Uma criança, quando emocionada, demonstra sua inquietude de diversas formas, pelo choro, pela violência, pela cólera, pelo carinho, mas, seja como for, geralmente o seu corpo é a "fonte" usada para essa expressividade. Assim, ao manifestar suas emoções e desejos, as crianças demonstram sua afetividade.

É necessário destacar também os estudos das obras de L. S. Vygotsky (1984), os quais têm importante relevância sobre a concepção do pensamento e da linguagem, bem como sobre a importância das relações entre os sujeitos no meio educacional para o desenvolvimento deles próprios. Para entender melhor o indivíduo, primeiro deve-se entender as relações sociais nas e pelas quais ele 
Contação de histórias em tempos de COVID-19: estabelecendo vínculos afetivos...

se desenvolve. Assim, as respostas individuais surgem das formas de vida coletiva.

As pesquisas desse autor buscam compreender como o contexto sociocultural pode influenciar e determinar o desenvolvimento humano, em especial, o desenvolvimento das crianças e suas aprendizagens. Segundo Vygotsky:

À luz do que eu e meus colaboradores aprendemos sobre as funções da fala na reorganização da percepção e na criação de novas relações entre as funções psicológicas, realizamos em crianças um amplo estudo de outras formas de atividades que usam signos, em todas as suas manifestações concretas (desenho, escrita, leitura, o uso de sistemas de números, etc.) (VYGOTSKY, 1984, p. 43).

A forma como as crianças se expressam funciona como "mola propulsora" da aprendizagem, e é por ela que se moldam as relações com os outros, sendo possível o desenvolvimento mental.

É primordial e indiscutível que crianças e docentes se relacionam de forma afetiva, e, para compreender essas relações, é possível expor dados acerca dos vínculos afetivos a partir das teorias de Pichon-Rivière (1998). O autor destaca que

[...] o vínculo é sempre um vínculo social; através da relação com essa pessoa repetese uma história de vínculos determinados em um tempo e em espaços determinados. Por essa razão, o vínculo se relaciona posteriormente com a noção de papel, de status e de comunicação (PICHON-RIVIĖRE, 1998, p. 3I).

Os vínculos afetivos estão diretamente relacionados à comunicação e às relações entre as pessoas. Como explica o autor supracitado, usa-se, como material de trabalho, a observação permanente da forma particular como cada sujeito relaciona-se com outros, elaborando um alicerce individual a cada caso e momento, chamado de vínculo. As formas como as pessoas se relacionam entre si permitem entender a importância dos vínculos afetivos.

Entende-se que "é possível estabelecer um vínculo, uma relação de objeto, com um objeto interno e também com um objeto externo" (PICHON-RIVIÈRE, 1998, p. 18). No atual contexto de isolamento social, do ponto de vista psicossocial, observam-se os vínculos externos que são as relações entre as pessoas, o respeito e a confiança que surgem.

Freire (1997), ao tratar da educação, destaca que professoras e professores precisam sentir afetividade pelas crianças, pois: "É impossível ensinar sem a capacidade forjada, inventada, bem cuidada de amar [...] É preciso ousar para jamais dicotomizar o cognitivo do emocional” (p. 8). Nota-se que docentes que trabalham com bebês e crianças pequenas vivenciam diariamente os vínculos afetivos sendo estabelecidos e o conhecimento infantil sendo produzido; nessa vivência, progridem e auto(trans)formam-se.

Ao destacar a auto(trans)formação, é necessário informar o significado desse termo, de acordo com o que vem sendo estudado, tendo como principal referência teórica os escritos de Paulo Freire 
e Marie Christine Josso, os quais englobam, como um de seus propósitos, a condição de “inacabamento" do ser humano.

A consciência de ser inacabado coloca o ser humano, de modo geral, e as professoras e os professores, de modo específico, neste escrito, em um movimento permanente de desenvolvimento pessoal e profissional, que também se estabelece, fundamentalmente, a partir de suas relações com os outros.

A compreensão de permanente pressupõe as idas e vindas de uma formação que está sempre em movimento e inacabada; que quanto mais avança mais percebe a necessidade de ser (re)pensada e, por vezes, de retroceder para (re)começar e refazer-se, em permanente processo de auto(trans)formação (ANDRADE; HENZ, 2018).

Nesse sentido, considera-se relevante realizar esse movimento, na prática docente, percebendo-se como sujeito inacabado, repleto da amorosidade indissociável da cognição e diretamente relacionado à produção de conhecimento, bem como da auto(trans)formação. Destacase a importância dos vínculos afetivos estarem presentes nas relações entre os docentes de Educação Infantil e as crianças; neste estudo, especificamente entre aqueles e os bebês, crianças pequenas.

\section{Leis que orientam a Educação Infantil em tempos de COVID-19 e a busca de possibilidades de manter os vínculos afetivos}

A Educação Infantil, primeira etapa da educação básica, na Lei de Diretrizes e Bases da Educação (LDB), Lei n 9.394/96, na Seção II, Art. 29, apregoa que "tem como finalidade o desenvolvimento integral da criança de até 5 (cinco) anos, em seus aspectos físico, psicológico, intelectual e social, complementando a ação da família e da comunidade" (BRASIL, I996). Assim, no que se refere ao aspecto psicológico, fica subentendido que a afetividade e os vínculos afetivos devem ser estabelecidos entre docentes e crianças.

No mesmo documento (LDB), Lei n 9.394/96, na Seção II, Art. 3I, consta que "II - carga horária mínima anual de 800 (oitocentas) horas, distribuída por um mínimo de 200 (duzentos) dias de trabalho educacional" (BRASIL, 1996). No entanto, nesse momento de pandemia, uma Medida Provisória - MP n 934/2020 - desobriga todas as redes de educação básica de cumprirem o mínimo de "200 dias efetivos de trabalho escolar, desde que cumprida a carga horária mínima anual de 800 horas ou a estabelecida pelos respectivos sistemas de ensino".

É importante destacar que, na LDB, não tem previsão nem normativa ofertando educação a distância, inclusive em circunstâncias emergenciais. Porém, o Conselho Nacional de Educação (CNE, 2020) sugeriu que as escolas "elaborassem orientações/sugestões" para as famílias ou responsáveis com propostas que pudessem ser realizadas com as crianças durante o período de isolamento social. 
Contação de histórias em tempos de COVID-19: estabelecendo vínculos afetivos...

Mesmo antes dessas orientações chegarem até as escolas, a protagonista desse relato de experiências tomou a iniciativa de organizar grupos (via WhatsApp), em uma página social, para manter contato com as famílias das crianças, no caso específico, do B-Il e do M-II. Em um primeiro momento, a intenção era manter os vínculos afetivos estabelecidos e ter informações sobre o bem estar das crianças, saber com quem estavam ficando em suas casas, com respeito e demonstrando cuidado com todos.

Em um segundo momento, a professora pensou em uma proposta pedagógica que as famílias pudessem apreciar as crianças, uma proposta lúdica, que proporcionasse prazer em ver e ouvir; assim, iniciou as contações de histórias. "Muitas histórias viajam dos livros para a voz do narrador e viceversa" (GIRARDELLO, 20I4, p. I2), possibilitando que os sujeitos, ao ouvirem uma história ser contada, viajem em suas imaginações.

As contações de histórias fazem parte da vivência dessa professora, a qual usa essa metodologia por acreditar na importância das histórias, como estímulo à imaginação, e como influência da leitura para os sujeitos. Seguindo a perspectiva de Freire, "a leitura do mundo precede sempre a leitura da palavra e a leitura desta implica a continuidade da leitura daquele" (20I I, p. 29). Primeiramente, os sujeitos leem o mundo e têm sua imaginação instigada; posteriormente, leem palavras e frases, de forma que, na atividade de contação de histórias, reside a esperança de formar novos leitores.

Nessa perspectiva, acredita-se ser possível "encantar por alimentar o nosso imaginário e dar mais brilho ao nosso mundo interior" (BUSATTO, 2012, p.17). Em tempos de isolamento social, a contação de histórias leva às crianças e seus familiares alguns momentos de descontração.

Mudar paradigmas e enfrentar uma nova realidade traz desafios. A professora aqui relatada enfrentou esses desafios e auto(trans)formou-se, reinventou-se em sua prática docente. Acostumada que estava com as contações de histórias de maneira presencial, prática recorrente em suas aulas, intimidou-se diante das câmeras, ao realizar as primeiras gravações de contações de histórias a serem encaminhadas às famílias. Mas, como Busatto (2012) apresenta, "é fundamental que se conte com o coração" (p.47). Dessa maneira, internalizando esse pensamento, concretizou-se o projeto, buscando, com a entonação da voz, encantar, prender a atenção das crianças e de seus familiares.

O trabalho teve retorno em forma de agradecimentos (algumas crianças mandavam figurinhas) e por meio de recados repletos de carinho. Foram recebidos áudios gravados pelas crianças e mensagens escritas pelos pais em nome de seus filhos, ainda não alfabetizados. Essa foi a motivação que faltava; a professora acreditou que poderia ir além.

Com o intuito de estreitar ainda mais os vínculos afetivos, a docente criou uma história, chamada "Vitor e a Centopeia"; confeccionou as personagens e fez a contação usando vozes diferentes e entonações especiais. A partir da audição dessa história, as crianças, juntamente com seus familiares,

Olhar de professor, Ponta Grossa, v. 24, p. I-8, e-16036.076, 202 I.

Disponível em <https://revistas2.uepg.br/index.php/olhardeprofessor> 
começaram a interagir, criando novas personagens e dando-lhes nomes diferentes. Os familiares fotografaram as crianças e suas criações; animais de estimação, bem como, bonecos, irmãos e amigos viraram personagens e ganharam novos nomes. Tudo compartilhado nos grupos virtuais.

"Gostaria de deixar expresso a minha crença de que contar histórias não é um privilégio de poucos, e sim uma tarefa acessível a quem se dispor a desenvolvê-la. Afinal, a prática ainda é o caminho mais seguro" (BUSATTO, 20I2, p.90). Nesse sentido, destaca-se a auto(trans)formação da professora que, refletindo sobre sua prática, olhando os vídeos, relacionando com estudos, percebeu a necessidade de aprimorar-se nas contações e assim o fez. E, em assim fazendo, percebeu o quanto valoriza e ama seu trabalho e o quanto a falta do contato físico com as crianças e seus familiares e a distância da instituição de ensino onde trabalha traz saudades.

\section{Considerações finais/conclusões}

O relato demonstra que os vínculos afetivos estão sendo mantidos nas turmas do B-Il e do MII. As demonstrações de carinho relatadas, o cuidado, o respeito e a confiança entre a professora, as crianças e seus familiares estão sendo indispensáveis para passar, com o mínimo de sequelas possível, por esse tempo de pandemia.

As proposições freireanas possibilitam refletir sobre os sentimentos, as relações estabelecidas entre os sujeitos, a amorosidade, a humildade, a ética, o diálogo e os temores, os quais estão presentes nos vínculos afetivos estabelecidos entre professores, bebês, crianças bem pequenas e famílias.

A emoção por conseguir manter os vínculos afetivos com os bebês e as crianças pequenas (por meio das histórias, dos vídeos com recados, dos áudios e das fotografias), bem como com suas famílias, e por saber que, até este momento, mesmo com as dificuldades que o COVID-19 a todos impõe, foi possível fazer a diferença, é indescritivel.

Ao compartilhar essa vivência pedagógica, cabe salientar que não é o foco aprofundar estudos sobre as obras literários, questões estéticas, mas compartilhar as vivências relatadas proporcionam um “caminhar para si” (JOSSO, 2010, p.I0), em meio a sensibilidade de descobertas, de saberes até então desconhecidos, como a percepção do potencial da voz humana ao transmitir uma mensagem, via contação de história. A possibilidade de modificar as emoções de quem ouve ou vê e de quem conta uma história é uma realidade nesse momento de pandemia. É uma boniteza em meio a tantas outras bonitezas e em meio às incertezas desse tempo.

\section{Referências}

ANDRADE, J. M. DOS S. DE; HENZ, C. I. Auto(trans)formação permanente com professores: em busca de uma compreensão político-epistemológica. Revista Educação e Cultura

Contemporânea, v. I5, n. 39 (2018). Disponível em

Olhar de professor, Ponta Grossa, v. 24, p. I-8, e-I I6036.076, 202 I.

Disponível em <https://revistas2.uepg.br/index.php/olhardeprofessor> 
<http://periodicos.estacio.br/index.php/reeduc/article/viewArticle/4740> Acesso em: 10 de mar. 2020.

BRASIL. Lei $\mathbf{n}^{\circ}$ 9.394, de 20 de dezembro de 1996. Estabelece as diretrizes e bases da educação nacional. LDB - Lei de Diretrizes e Bases da Educação. Disponível em:

<http://www.planalto.gov.br/ccivil_03/leis/L9394.htm>. Acesso em: I8 set. 2015.

BRASIL. Ministério da Educação. Conselho Nacional de Educação. Parecer CNE/CP n 5/2020, de 28 de abril de 2020. Reorganização do Calendário Escolar e da possibilidade de cômputo de atividades não presenciais para fins de cumprimento da carga horária mínima anual, em razão da Pandemia da COVID-19. Disponível em:

$<$ https://normativasconselhos.mec.gov.br/normativa/pdf/CNE PAR CNECPN52020.pdf>. Acesso em 06 de mai. de 2020.

BUSATTO, C; Contar e Encantar: Pequenos segredos da narrativa. Petrópolis, Vozes, 2012.

CHAVES, P. M; KOEHLER, A. D. Negar a leitura literária hoje para conter a organização política amanhã: formação estética para quem? Revista Diálogo Educacional, Curitiba, v. 2I, n. 68, p.409434, jan./mar. 202I. Disponível em: https://redib.org/Record/oai_revista4804-revista-di\%C3\%Allogoeducacional. Acesso em: I 2 abr. 202I.

FREIRE, P. A importância do ato de ler. São Paulo: Cortez, 201 I.

FREIRE, P. Professora sim, tia não: Cartas a quem ousa ensinar. São Paulo, Olho D’agua, 1997.

GIRARDELLO, G. Uma Clareira no Bosque: Contar história na escola, Campinas, Papirus, 2014.

JOSSO, M-C, Caminhar para si. Porto Alegre, ARTMED, 2010.

PICHON-RIVIÈRE, E. Teoria do Vínculo. 6. ed. São Paulo: Martins Fontes, 1998.

VYGOTSKY, L. S. A Formação Social da Mente. São Paulo, 1984.

WALLON, H. A. Evolução Psicológica da Criança. Lisboa, EDIÇÕES 70, 2005.

Recebido em: I5 de junho de 2020.

Versão corrigida recebida em: 15 de abril de 2021.

Aceito em: 14 de junho de 202 I.

Publicado online em: 30 de julho de 2021 .

Olhar de professor, Ponta Grossa, v. 24, p. I-8, e-16036.076, 2021.

Disponível em <https://revistas2.uepg.br/index.php/olhardeprofessor> 